\title{
๑ัฐorwort.
}

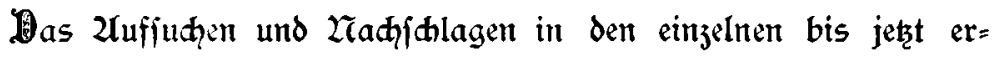
fofienenen 33 Jahrgängen $(35$ Bänden) des Juftizminifterialblattes für das Köntigreith Bapern erfordert fehr viel zeeit und 2kühhe. Diefe $z^{\mathfrak{u}}$ erfparen und der praris ein möglithit bequemes und braudfbares Giilfsmittel für rajhis und erfolgreidges Zurehtfinden in den im Jufitiz= minifterialblatt veröffentlidhten Beftinmungen, fofern diefelben now giltig und von allgemeiner Bedeutung find, ju bieten, daju ift vorliegende $\mathfrak{Z}$ rbeit beftimmt.

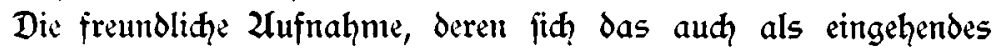

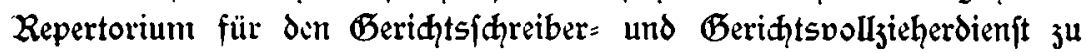
gebrauchende Regifter bei feinem erftmaligen Erifheinen int Jahre 1882 ju erfreuen hatte, fowie die vielfachen Zaahfragen naḑ dem binnen Jahresfrifit vollfitünoig vergriffenen Budhe gaben $\mathcal{D}_{\text {eranlaffung }}$ ju vormürfiger Zien=21uflage, in melcher audh die bis 1. Januar 1896 erfigienenen Bejtimmungen Berü:ffichtigung fanden.

$2 \pi u ̈ g e$ das Regifter aud in feimer neuen Geftalt $\mathfrak{D}$ ielen ein will=

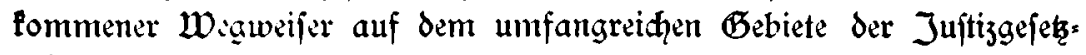
gebung wirdin.

sirtoan i. ว̧., 18. Januar 1896.

\section{Der Derfafier.}


